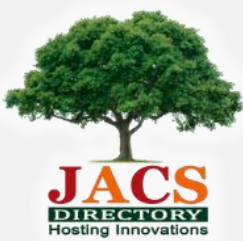

Journal of Nanoscience and Technology

\title{
Reduced Graphene Oxide/CuS Nanocomposite: An Efficient Photocatalyst for Degradation of Crystal Violet
}

\author{
Ruchi $^{1}$, Avinash Kumar Rai ${ }^{1}$, Meghavi Gupta ${ }^{1}$, Rakshit Ameta1,2,*, Suresh C. Ameta1 \\ ${ }^{1}$ Department of Chemistry, PAHER University, Udaipur - 313 003, Rajasthan, India. \\ ${ }^{2}$ Department of Chemistry, J.R.N. Rajasthan Vidyapeeth (Deemed to be University), Udaipur - 313 001, Rajasthan, India.
}

\section{ART ICLE DETAILS}

\section{Article history:}

Received 28 February 2019

Accepted 05 April 2019

Available online 06 May 2019

Keywords:

Photocatalytic Degradation

Reduced Graphene Oxide

Copper Sulphide

Crystal Violet

\begin{abstract}
A B S T R A C T
Scarcity of both quality and quantity of water has become a burning problem all over the world. Pollution by dyes constitutes a major portion. Advanced oxidation processes have been developed as green chemical technology to combat against water pollution. Graphene oxide is a 'miracle material' with 2D honeycomb structure, which is also known for enhancement of photocatalytic activity of different semiconductors. In this paper, reduced graphene oxide with a combination of copper sulphide ( $\mathrm{rGO}$-CuS composite) is used to remove crystal violet photocalatytically from waste water. The photocatalytic performance of $\mathrm{rGO} / \mathrm{CuS}$ composite and $\mathrm{CuS}$ was evaluated by using a model system of crystal violet. Optimum conditions obtained for photocatalytic degradation of crystal violet are: $\mathrm{pH}=5.0$, [Crystal Violet $]=3.40 \times 10^{-5} \mathrm{M}$, amount of composite $=0.12 \mathrm{~g}$ and light intensity $=50.0 \mathrm{mWcm}^{-2}$. It was observed that composite showed good photocatalytic activity as compared to individual CuS ( $48.1 \%$ increase) and rGO $(32.8 \%$ increase).
\end{abstract}

\section{Introduction}

Wastewaters from food colouring, cosmetics, paper and textile industries are polluted by dyes. When these coloured effluents enter rivers or any other surface water system, they upset the biological activity. Ground-water systems are also affected by these pollutants because of leaching from the soil. Dyes are frequently used in various industries. During its production and application in dyeing, a huge amount of effluent water containing high concentration of organic dyes is generated. Due to high solubility of dyes in water, it is quite difficult to remove these from waste water. Many dyes may cause allergy, skin irritation, and various health issues like nausea, vomiting, profuse sweating or some time mutation in humans, even some of them are carcinogenic. The conventional methods for treating dye-containing wastewaters are: electrochemical reduction method [1], adsorption [2-3], coagulation and flocculation [4-6], nanofiltration or reverse osmosis [7-9] etc. These are widely used for removal of organic pollutants.

Recently, advanced oxidation processes (AOPs) have been focused for degradation of dye in waste water due to their advantages such as ecofriendly, economically viable and capability to degrade many dyes or organic pollutants present in water. Photocatalysis is one of the advance oxidation processes and it is mainly carried out under irradiation of light and presence of suitable photocatalytic materials. The photocatalytic activity of the photocatalytic materials mainly depends on the band gap, surface area, and generation of electron-hole pair. It has been observed that the surface area plays a major role in photocatalytic degradation of dyes, which leads to the higher adsorption of dye molecule on the surface of photocatalyst and enhancement of photocatalytic activity [10]. Several photocatalysts like $\mathrm{TiO}_{2}, \mathrm{SiO}_{2}, \mathrm{ZnO}, \mathrm{BiOI} / \mathrm{BiOBr}, \mathrm{SnO}_{2}, \mathrm{Ag}_{3} \mathrm{VO}_{4}$, etc. are used to degrade various pollutants. These photocatalysts are used as individual or after making composites with some natural, synthetic or carbon-based adsorbents [11-23]. In the present work, reduced graphene oxide and copper sulphide (rGO-CuS) composite was used for the removal of crystal violet.

\section{Experimental Methods}

\subsection{Preparation of Composite}

The composite of rGO and CuS was fabricated by mechanochemical method following a top-down approach. Equal amounts of rGO and CuS were ground with agar mortar-pestle. This synthesised composite was characterised by several techniques like XRD, FESEM and EDX and used in experiment.

\subsection{Characterisation}

XRD of rGO and rGO-CuS were recorded with the help of X-ray diffractometer (XPERT-PRO model) in the range $20^{\circ}$ to $80^{\circ}$. A characteristic peak of $\mathrm{rGO}$ was present around $25^{\circ}$. The crystal size of $\mathrm{rGO}-$ $\mathrm{CuS}$ was calculated using Debye - Scherrer equation. Its average particle size was found to be about $43.95 \mathrm{~nm}$. FESEM was recorded on XFlash 6130 (Bruker) (Fig. 1). FESEM image of rGO-CuS is in the favour of CuS attached to $\mathrm{rGO}$, which provides more surface area for better photocatalytic activity. It is also easy to transfer photogenerated electrons in the composite permitting electron-hole recombination. The composition of composite was also determined with the help of EDAX. The results are given in Fig. 2 and Table 1.

\subsection{Photodegradation Process}

Stock solution of $1.0 \times 10^{-3} \mathrm{M}$ concentration was prepared by dissolving $0.0408 \mathrm{~g}$ of crystal violet dye in $100.0 \mathrm{~mL}$ of doubly distilled water. Further working solutions were prepared from this stock solution as and when required. The absorbance of experimental solution was determined by spectrophotometer at $\lambda \max =540 \mathrm{~nm}$. Experimental solutions were irradiated with a $200 \mathrm{~W}$ tungsten lamp. Control experiments were performed, which indicates that the degradation required both; light and composite. The desired $\mathrm{pH}$ of the reaction mixture was adjusted by addition of standard $0.1 \mathrm{~N}$ sulfuric acid and $0.1 \mathrm{~N}$ sodium hydroxide solutions. A decrease in absorbance of crystal violet dye solution was observed with increasing time of exposure. A plot of $1+\log$ A against time was found to be linear, which indicates that the photocatalytic degradation of crystal violet follows pseudo-first order kinetics. 

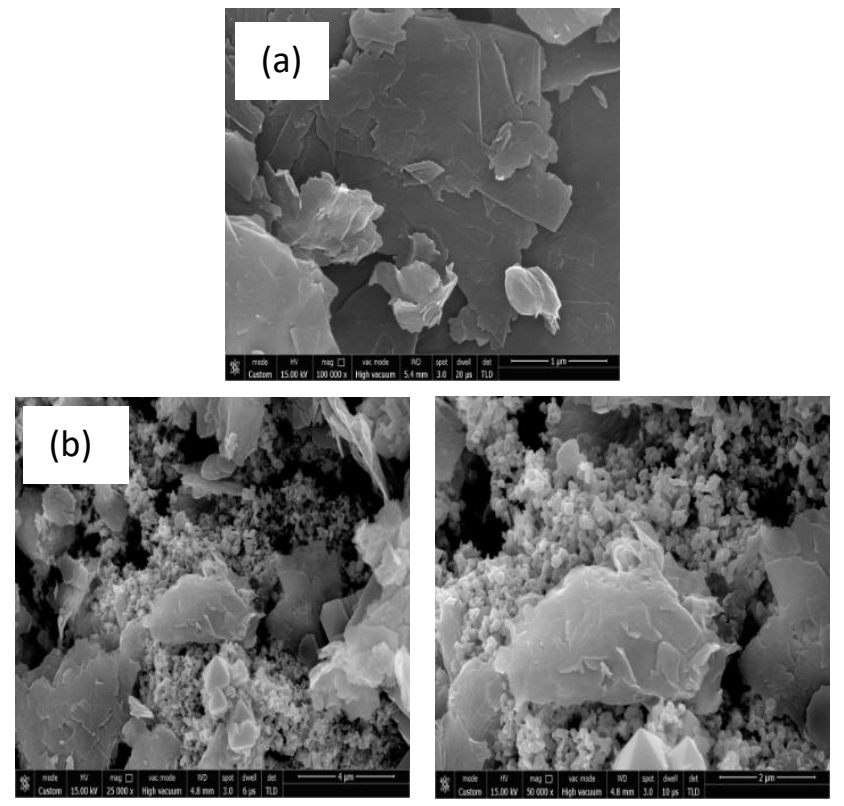

Fig. 1 FESEM image of a) rGO and b) CuS-rGO

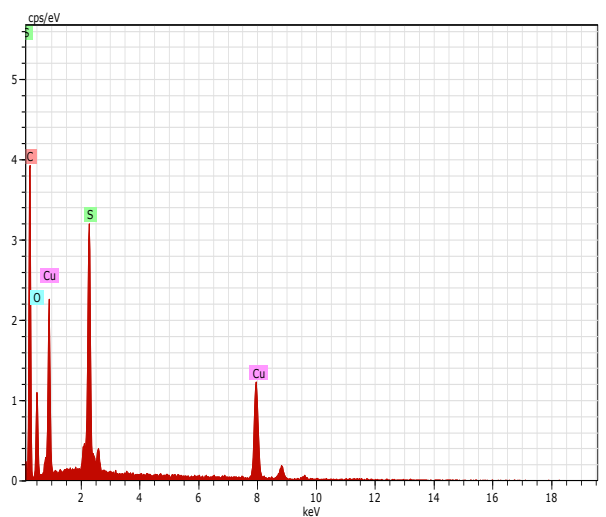

Fig. 2 EDAX image of rGO-CuS

Table 1 EDAX results of rGO-CuS

\begin{tabular}{ll}
\hline Element & Weight $(\%)$ \\
\hline Carbon & 56.16 \\
Oxygen & 15.81 \\
Copper & 19.39 \\
Sulphur & 8.64 \\
\hline
\end{tabular}

\section{Results and Discussion}

The rate constant for degradation was measured with the help of equation, $\mathrm{k}=2.303 \times$ slope, Typical runs of $\mathrm{rGO}, \mathrm{CuS}$ and $\mathrm{rGO}-\mathrm{CuS}$ composite is graphically represented in Fig. 3. The rate constant was found to be $1.54 \times 10^{-4} \mathrm{~s}^{-1}$ as compared to individual $\mathrm{rGO}\left(1.16 \times 10^{-4} \mathrm{~s}^{-1}\right)$ and $\mathrm{CuS}$ $\left(1.04 \times 10^{-4} \mathrm{~s}^{-1}\right)$, at optimum values of $\mathrm{pH}=5.0$, crystal violet concentration $=3.40 \times 10^{-5} \mathrm{M}$, amount of $\mathrm{rGO}, \mathrm{CuS}$, composite $=0.12 \mathrm{~g}$ and light intensity $=50.0 \mathrm{mWcm}^{-2}$. Different rate affecting parameters were varied to obtain the maximum rate of degradation for photocatalytic degradation of crystal violet.

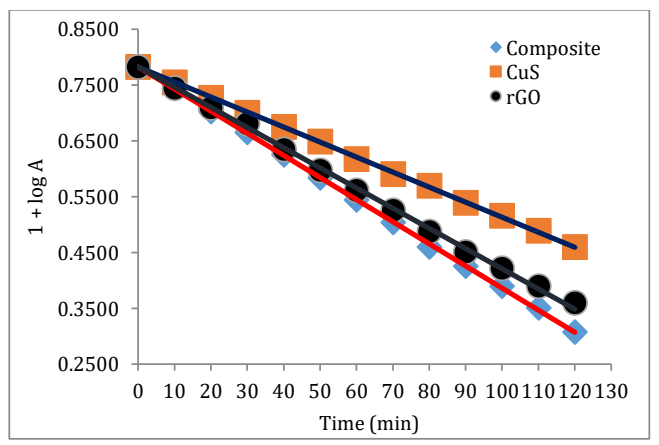

Fig. 3 Typical runs of rGO, CuS and rGO-CuS composite

https://doi.org/10.30799/jnst.210.19050207

Cite this Article as: Ruchi, Avinash Kumar Rai, Meghavi Gupta, Rakshit Ameta, Suresh C. Ameta, Reduced graphene oxide/CuS nanocomposite: An efficient photocatalyst for degradation of crystal violet, J. Nanosci. Tech. 5(2) (2019) 673-675.

\subsection{Effect of $p H$}

The $\mathrm{pH}$ of the solution may affect the degradation of crystal violet. The effect of $\mathrm{pH}$ on the rate of degradation of crystal violet was investigated in the $\mathrm{pH}$ range 4.0-8.5 and is shown in Fig. 4. It was observed that the rate of photocatalytic degradation increased with increase in $\mathrm{pH}$ up to $\mathrm{pH} 5.0$ but on increasing $\mathrm{pH}$ above this limit, rate of the reaction gradually declined. Maximum degradation was found in acidic medium. As $\mathrm{pH}$ was decreased, acidic nature will increase and adsorption of $\mathrm{H}^{+}$ions will be more on composite. A decrease in reaction rate may be due to force of repulsion between cationic dye molecules and + ve charged surface of the composite.

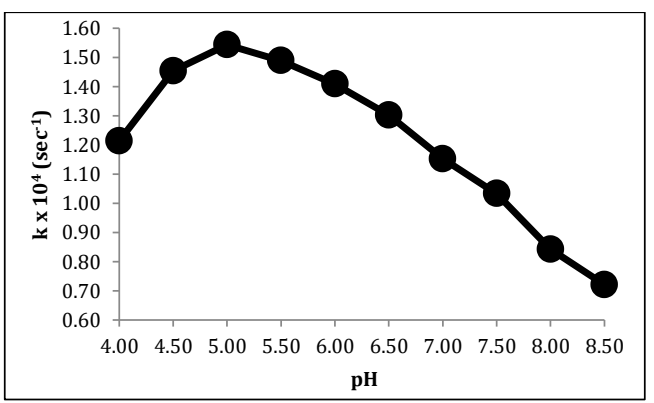

Fig. 4 Effect of $\mathrm{pH}$

\subsection{Effect of Dye Concentration}

The effect of dye concentration was observed by taking different concentrations of Crystal violet. The results are graphically represented in Fig. 5. It was observed that the rate of photocatalytic degradation increases with an increase in dye concentration and attained optimum rate at $3.40 \times$ $10^{-5} \mathrm{M}$. It may be explained that as the concentration of dye was increased, a large number of dye molecules were available for excitation and energy transfer and as a result, the rate of photocatalytic degradation increased appreciably. It was found that the rate of photocatalytic degradation decreased with an increase in the concentration of dye further.

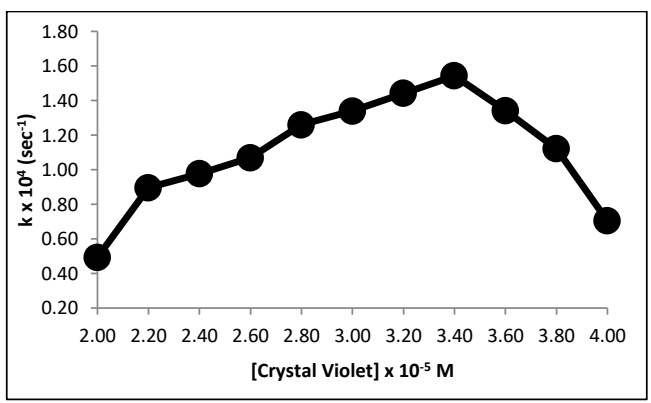

Fig. 5 Effect of crystal violet concentration

This may be attributed to the fact that after a certain dye concentration, the dye itself starts acting as an internal filter for incident light, and hence, it will not allow the desired light intensity to reach the surface of the composite. As a consequence, decrease in rate of photocatalytic degradation was observed.

\subsection{Effect of Amount of Composite}

The amount of composite may also affect the degradation of dye and hence, different amounts of rGO-CuS composite were used. Their results are graphically represented in Fig. 6. It was observed that the rate of photocatalytic degradation increased with increase in amount of composite up to a certain value $(0.12 \mathrm{~g})$, but on further increasing the amount of composite, the rate of the reaction gradually declined.

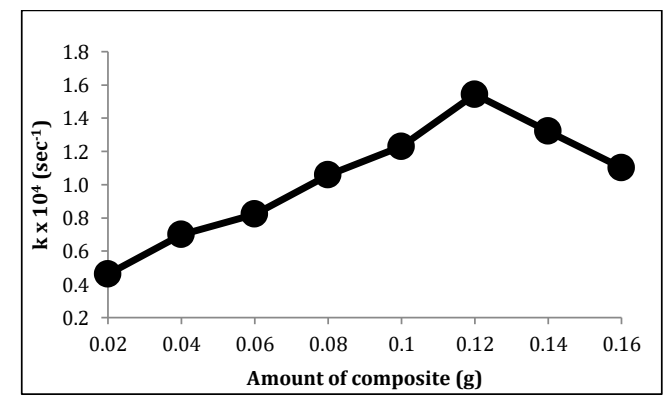

Fig. 6 Effect of amount of composite 
As the amount of composite was increased, the exposed surface area of the composite increases but above $0.12 \mathrm{~g}$, an increase in the amount of composite will only increases the thickness of layer of the composite and not its exposed surface area. As a result, the rate of degradation decreases slightly.

\subsection{Effect of Light Intensity}

The effect of light intensity on the photocatalytic degradation of crystal violet was also investigated by changing the distance between the light source and the exposed surface area of composite. The variation of results is graphically presented in Fig. 7. It was observed that as the light intensity was increased, the rate of photodegradation increases upto a certain value $\left(50.0 \mathrm{mWcm}^{-2}\right)$. Further increase in light intensity results in decrease in the rate of photodegradation.

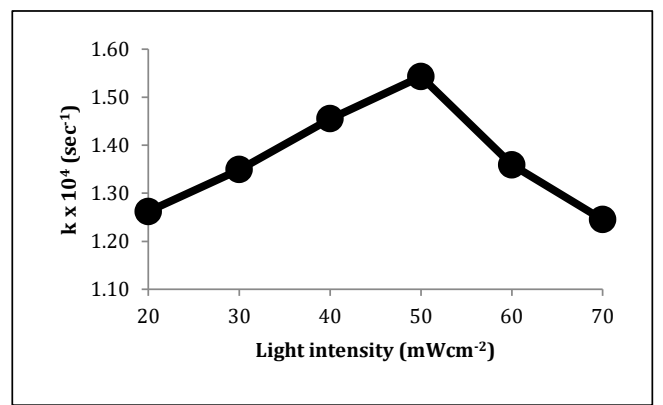

Fig. 7 Effect of light intensity

This observation may be explained on the basis that as the light intensity was increased, number of photons striking per unit area per unit time increases, which leads to higher rate of degradation. Further increase in the light intensity may cause some other thermal side reactions so the rate of the reaction was decreased and therefore, higher light intensities were avoided.

\subsection{Mechanism}

On the basis of above observations, a tentative mechanism for photocatalytic degradation of crystal violet is proposed as follows:

\begin{tabular}{|c|c|c|}
\hline${ }^{1}$ Crystal violet $_{0}$ & hv & ${ }^{1}$ Crystal violet $_{1}$ \\
\hline${ }^{1}$ Crystal violet $_{1}$ & ISC & ${ }^{3}$ Crystal violet $_{1}$ \\
\hline $\mathrm{CuS}$ & hv & $\mathrm{CuS}\left\{\mathrm{e}^{-}(\mathrm{CB})+\mathrm{h}^{+}(\mathrm{VB})\right.$ \\
\hline $\mathrm{CuS}\left(\mathrm{e}^{-}\right)+\mathrm{rGO}$ & & $\mathrm{rGO}\left(\mathrm{e}^{-}\right)$ \\
\hline $\mathrm{rGO}\left(\mathrm{e}^{-}\right)+\mathrm{O}_{2}$ & & $\mathrm{O}_{2^{-}}^{0^{-}}+\mathrm{rGO}$ \\
\hline $\mathrm{O}_{2}{ }^{-}+\mathrm{H}^{+}$ & & $\mathrm{HO}_{2}$ \\
\hline $\mathrm{HO}_{2} \cdot+{ }^{3}$ Crystal violet $_{1}$ & & Leuco Dye \\
\hline Leuco Dye & & Oxidized products \\
\hline
\end{tabular}

Leuco Dye

Oxidized products

\section{Conclusion}

People from all around the world are facing the problem of everincreasing water pollution and as a consequence, there is a scarcity of potable water. Nanocomposite of $\mathrm{CuS}$ with $\mathrm{rGO}$ show potential application in the treatment of waste water containing dyes. Using this composite, crystal violet was successfully degraded with higher efficiency as compared to individual component CuS (48.1\%, increase) or rGO (32.8\%, increase). The present work will open new avenues for further researches on use of rGO-photocatalyst composites as an eco-friendly method of waste water treatment in coming decades.

\section{References}

[1] H.P. Sachin, B.M. Praveen, Treatment of industrial azo dye effluents by electrochemical technique and its COD measurement, J. Applicable Chem. 6 (2017) 1149-1157.

[2] R. Dandge, M. Ubale, S. Rathod, Adsorption of crystal violet dye from aqueous solution onto the surface of green peas shell (GPS), J. Applicable Chem. 5 (2016) 792-801.

[3] T. Nargawe, A.K. Rai, R. Ameta, S.C. Ameta, Adsorption study for removal of crystal violet dye using MMT-MWCNTs composite from aqueous solution, J. Applicable Chem. 7 (2018) 1252-1259

[4] A. Szygu, E. Guibal, M.A. Palacın, M. Ruiz, A.M. Sastre, Removal of an anionic dye (Acid Blue 92) by coagulation-flocculation using chitosan, J. Environ. Manag. 90 (2009) 2979-2986.

[5] M. Riera-Torres, C. Gutiérrez-Bouzán, M. Crespi, Combination of coagulationflocculation and nanofiltration techniques for dye removal and water reuse in textile effluents, Desalination 252 (2010) 53-59.

[6] B. Liu, H. Zheng, Y. Wang, X. Chen, C. Zhao, Y. An, X. Tang, A novel carboxyl-rich chitosan-based polymer and its application for clay flocculation and cationic dye removal, Sci. Total Environ. 640-641 (2018) 107-115

[7] E. Kurt, D.Y. Koseoglu-Imer, N. Dizge, S. Chellam, I. Koyuncu, Pilot-scale evaluation of nanofiltration and reverse osmosis for process reuse of segregated textile dye wash wastewater, Desalination 302 (2012) 24-32.

[8] M. Liu, Z. Lü, Z. Chen, S. Yu, C. Gao, Comparison of reverse osmosis and nanofiltration membranes in the treatment of biologically treated textile effluent for water reuse, Desalination 281 (2011) 372-378.

[9] A. Anand, B. Unnikrishnan, J.Y. Mao, H.J. Lin, C.C. Huang, Graphene-based nanofiltration membranes for improving salt rejection, water flux and antifouling-A review, Desalination 429 (2018) 119-133.

[10] S. Natarajan, H.C. Bajaj, R.J. Tayade, Recent advances based on the synergetic effect of adsorption for removal of dyes from waste water using photocatalytic process, J. Environ. Sci. 65 (2018) 201-222.

[11] W. Dong, C.W. Lee, X. Lu, Y. Sun, W. Hua, et al., Synchronous role of coupled adsorption and photocatalytic oxidation on ordered mesoporous anatase $\mathrm{TiO}_{2}-$ $\mathrm{SiO}_{2}$ nanocomposites generating excellent degradation activity of $\mathrm{RhB}$ dye, Appl. Catal. B: Environ. 95 (2010) 197-207.

[12] V.K. Gupta, R. Jain, A. Mittal, T.A. Saleh, A. Nayak, S. Agarwal, S. Sikarwar, Photocatalytic degradation of toxic dye amaranth on $\mathrm{TiO}_{2} / \mathrm{UV}$ in aqueous suspensions, Mater. Sci. Eng. C 32 (2012) 12-17.

[13] J. Cao, B. Xu, H. Lin, B. Luo, S. Chen, Chemical etching preparation of BiOI/BiOBr heterostructures with enhanced photocatalytic properties for organic dye removal, Chem. Eng. J. 185-186 (2012) 91-99.

[14] B. Li, H. Cao, ZnO@graphene composite with enhanced performance for the removal of dye from water, J. Mater. Chem. 21 (2011) 3346-3349

[15] I. Fatimah, S. Wang, D. Wulandari, $\mathrm{ZnO} /$ montmorillonite for photocatalytic and photochemical degradation of methylene blue, Appl. Clay Sci. 53 (2011) 553560.

[16] M.A. Ahmed, E.E. El-Katori, Z.H. Gharni, Photocatalytic degradation of methylene blue dye using $\mathrm{Fe}_{2} \mathrm{O}_{3} / \mathrm{TiO}_{2}$ nanoparticles prepared by sol-gel method, J. Alloys Compd. 553 (2013) 19-29.

[17] Y.B. Onundi, A.A. Mamun, M.F. Al Khati, M.A. Al Saadi, A.M. Suleyman, Heavy metals removal from synthetic wastewater by a novel nano-size composite adsorbent, Int. J. Environ. Sci. Technol. 8 (2011) 799-806.

[18] S. Wanga, D. Li, C. Suna, S. Yang, Y. Guan, H. He, Synthesis and characterization of g- $\mathrm{C}_{3} \mathrm{~N}_{4} / \mathrm{Ag}_{3} \mathrm{VO}_{4}$ composites with significantly enhanced visible-light photocatalytic activity for triphenylmethane dye degradation, Appl. Catal. B: Environ. 144 (2014) 885-892.

[19] A. Duta, M. Visa, Simultaneous removal of two industrial dyes by adsorption and photocatalysis on a fly-ash- $\mathrm{TiO}_{2}$ composite, J. Photochem. Photobiol. A: Chem. 306 (2015) 21-30

[20] R. Cai, J.G. Wu, L. Sun, Y.J. Liu, T. Fang, et al., 3D graphene/ZnO composite with enhanced photocatalytic activity, Mater. Design 90 (2016), 839-844

[21] K. Alamelu, B.M. Jaffar Ali, $\mathrm{TiO}_{2}-\mathrm{Pt}$ composite photocatalyst for photodegradation and chemical reduction of recalcitrant organic pollutants, J. Environ. Chem. Eng. 6 (2018) 5720-5731

[22] W. Zhang, L. Zhou, J. Shi, H. Deng, Synthesis of $\mathrm{Ag}_{3} \mathrm{PO}_{4} / \mathrm{G}_{-} \mathrm{C}_{3} \mathrm{~N}_{4}$ composite with enhanced photocatalytic performance for the photodegradation of diclofenac under visible light irradiation, Catalysts 8 (2018) 45-1-15.

[23] T.A. Kurniawan, L. Yanyan, T. Ouyang, A.B. Albadarin, G. Walker, $\mathrm{BaTiO}_{3} / \mathrm{TiO}_{2}$ composite-assisted photocatalytic degradation for removal of acetaminophen from synthetic wastewater under UV-vis irradiation, Mater. Sci. Semicond. Proc. 73 (2018) 42-50. 